A letter from her doctor, dated November, 1916, states that the headaches are very severe again, but the vision still much the same.

Nystagmus is referred to by Uhthoff ${ }^{56}$ as a rare symptom occurring in about 6 per cent. of cases of acromegaly, and less often in pituitary tumours without trophic disturbance.

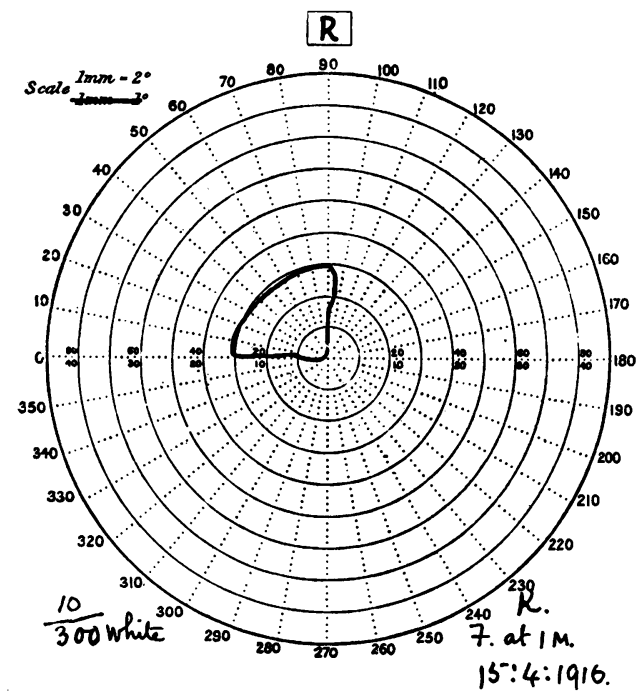

FIG. 25.

CASE XXIV.-K., male, aged 29 years, seen April, 1916, under the care of Professor Gulland. Pituitary infantilism with enlarged sella Turcica. Appearance is that of a boy of 13 or 14 years. R.V. = counting fingers at 1 metre, L.V. $=6 / 24$. Discs deeply cupped and slightly pale, but not definitely atrophic in appearance. Fig. 25 shows field of R.E. The left field showed complete temporal loss without obvious differentiation into quadrants on the nasal side. The patient's mentality, however, prevented a more detailed or prolonged examination.

( $T$ o be continued.)

\title{
THE RETINAL SIGNS OF ARTERIO-SCLEROSIS COMPARED WITH THOSE DUE SIMPLY TO INCREASED BLOOD PRESSURE.*
}

BY

\author{
P. C. BARDSLEy, \\ LONDON.
}

IN 1897, in Volume XVIII of the Transactions of the Ophthalmological Society of the United Kingdom, Mr. Marcus Gunn published his monumental work on the retinal signs of arterial sclerosis.

* Read in the Section of Ophthalmology of the Royal Society of Medicine on February 7th, 1917. 
From the clinical side there has been little or no advance since.

$\mathrm{Mr}$. Gunn laid down four cardinal signs of sclerosis of retinal vessels, viz. :-

1. A tendency to tortuosity of the arteries, especially the smaller vessels.

2. Variation in the calibre of the vessels, especially sudden diminution for a short length passing again into normal size.

The calibre is apparently sometimes narrowed by nodules in the vessel walls, imparting to the vessels a beaded appearance.

3. Alteration of the normal light streak. This becomes very much brighter and very much more sharply defined.

4. Indentation of veins, either by super-pressure of the artery crossing above the vein, or infra-pressure from crossing below. When there is considerable indentation there is great obstruction followed by all the sequelæ of back pressure, viz., stasis, thrombus, œdema, and hæmorrhages into the surrounding tissues.

It is necessary for the clear understanding of this paper to keep these four signs all the time before us: tortuosity; variation of calibre ; alteration of light streak ; indentation of veins.

These signs of Marcus Gunn's have been confirmed by the ophthalmoscopic examinations of hundreds of observers since ; but no additional sign of any importance has been added. de Schweinitz emphasises the brick-red discolouration of the disc as a late but important sign ; this is due to the dilatation of the capillaries and is the consequence of the venous obstruction and back pressure.

Mr. Gunn was undoubtedly one of the first who advanced the opinion that arterio-sclerosis was not confined to old age, and that old age was not alone productive of these changes.

The prognosis of these cases was at first regarded as very bad indeed. Some years back, however, I came to the conclusion that this dire prognosis did not apply nearly so universally as was at first supposed. In following up the after-history of these patients I found that some with very advanced mischief, such as considerable retinal œdema with hæmorrhages, improved marvellously under treatment, and in some cases, to my surprise, the cardinal signs largely disappeared.

At times, also, cases were published in the journals, such as the following, which appeared in the British Medical Journal of August 6th, 1910. The case was published by Dr. W. M. Crofton, lecturer in special pathology, University College, Dublin, and was entitled :

\section{"Recovery from Apparent Arterial Sclerosis."}

This is the gist of Dr. Crofton's publication :-

Patient, aged 60, manager of a large commercial concern, had led a strenuous life. He was very short of breath, and suffered from palpitation. A specialist diagnosed cardio-sclerosis, and ordered 
him a sea voyage. His urine contained a trace of albumen, but no sugar.

Owing to a feeling of weight on the top of his head and aching of the eyeballs, he was sent to Mr. Claud A. Worth. Mr. Worth's report was :-

"Retinal arteries are very small and tortuous. Central light streak very wide. Where an artery crosses a vein, the latter is so compressed as to be apparently interrupted. No retinal œdema. No hæmorrhages."

Patient was placed under treatment for three months, after which he returned to work. Two months later he again saw Mr. Worth, who reported as follows :-

"Retinal arteries are large and have lost the 'silver wire' appearance. The appearance of interruption of the veins is much less marked ; in fact, the arteries appear normal for a man of his years."

The publication of cases like this, and my own observations, compelled me to ask myself repeatedly this question : Can sclerosed vessels change in appearance in this manner? Are these cases, which often show advanced signs (for surely back-pressure and œdema must pass as very advanced signs), are these advanced cases, which improve so much, incipient sclerosis, or are they sclerosis at all ? We know that iodides may produce absorption of round-celled infiltration; and we may reasonably conceive of resolution of the hypertrophied muscle cells and elastic fibres; but are we justified in expecting the disappearance of organized granulation fibres and connective tissue? General experience answers-No. May not the signs, then, be due to some cause other than sclerosis?

Again, I observed that these changes could occur with startling rapidity. I saw patients, whose eyes I had carefully examined only a very short time before (in some cases only a few days), and whose vessels had appeared perfectly healthy and normal, and I saw those patients after a severe attack of influenza, scarlet fever, or some other toxæmia, develop these signs of retinal sclerosis, with deep indentation of veins, and a macular œdema sufficient to reduce their vision from normal to $6 / 12$.

It was impossible to believe that an advanced fibrosis had occurred in a few days, nay, in a day or two. It was equally impossible to believe that these signs could be due to round-celled infiltration preliminary to fibrosis, for in many cases, after lasting for months, the signs largely or entirely disappeared. In these months the infiltration would surely have become organised.

I became certain, then, that these cardinal signs of Marcus Gunn did not necessarily indicate arterial sclerosis, but were often due to some accessory cause.

Many years ago at Moorfields, when observing these cases, I 
began taking the blood pressures of the patients with a Riva-Rocci manometer. In nearly all the cases the blood pressure was raised considerably above the normal, and in many cases excessively so. Often the patients sought advice for headaches which they thought were due to their eyes, but which were not relieved by suitable lenses. I commenced treating these patients with depressor drugs, strict diet, exercise, baths, etc., as recommended by the various authorities on blood pressure. I noticed that when I was successful in lowering the blood pressure to any considerable extent, along with the relief of the head symptoms, the ophthalmoscopic signs of retinal sclerosis appreciably diminished.

Increased blood pressure, then, accounted for some of the cardinal signs.

When the toxic cause of the high blood pressure was traced and was successfully removed, such as by the complete clearing of the mouth of septic stumps, the improved changes in the retinal vessels were still more remarkable.

If, then, some of these cardinal signs were produced by the high pressure of the blood alone without sclerosis, while other signs were due to sclerosis, it became important to decide if it was possible to distinguish between the changes due to the simple raised pressure and those due to the more serious sclerosis. In the discussion on retinal vascular disease at the Ophthalmological Society, during the Session 1912-1913, I ventured to state that I thought it was possible with the ophthalmoscope to distinguish between the signs of high tension and the signs of angio-sclerosis.

The following seem to me the distinguishing characteristics :-

In simple high tension,-

1. The vessels have an appearance of uniform distension and fulness.

2. The light streak is broadened out : it may be greatly increased, apparently reaching almost the whole breadth of the vessel.

3. The light streak is very much brighter than normal, the brilliancy increasing with the increase of the tension, until with very high tension it becomes like bright copper wire (not silver wire).

4. The tight arteries indent the veins; with medium high tension they indent them slightly, with very high tension they indent them deeply, leading to back-pressure and all its consequences.

The following signs indicate sclerosis :-

1. Irregular tortuosity, especially of the smaller twigs.

2. Increased brilliancy of the light streak, while at the same time the light streak appears narrower and more central.

3. Irregularity of calibre and beading are sure indications of sclerosis.

4. General diminution in the size of the vessels and "silver wire" reflex show advanced sclerosis. 
Now, of course, these two conditions of high tension and sclerosis very frequently coincide, but not by any means always. I have seen cases of definite early sclerosis of the retinal vessels with only slightly raised blood pressure. The blood pressure has been suddenly raised by some toxic infection, or by artificial means, and the above signs of high tension in the retinal vessels have been added to the previous ones. These signs have again disappeared on lowering the blood pressure or eliminating the toxic cause. On the other hand, in advanced "silver wire" sclerosis, I have never seen the signs of sclerosis removed. I have seen some diminution in the intensity of reflex when the vascular pressure has been lowered by drugs, or the heart pressure has failed; the ophthalmoscopic signs of sclerosis always remained in evidence.

The question whether continued high blood pressure induces sclerosis perhaps scarcely concerns us here. But, for my part, I do not think it necessarily does. For instance, there may be a raised pressure from aortic disease, with perfectly compensated hypertrophy. This may last for a lifetime without any signs of vascular sclerosis becoming evident. Again, in myxœdema the blood tension is raised (probably from the imbalance of the suprarenal and thyroid secretions) without signs, that is, retinal signs of sclerosis.

When continued high tension is followed by sclerosis, this sclerosis may be due to the same toxin which caused the high tension.

Now, to confirm the above deductions, I called in the assistance of my House Surgeon, Mr. du Toit. We took a number of cases in the Salisbury General Infirmary, and artificially raised the blood pressure.

We selected, as far as possible, healthy cases from the surgical side of the Infirmary, such as males admitted for radical cures of hernia. We carefully examined the retinal vessels of each patient by a good illumination from a fixed light, and with a mydriatic in the eyes ; and we made careful notes of the conditions of the vessels. We then took the blood pressure with a manometer and noted it carefully from two or three examinations. We next administered a hypodermic injection of 5-8 minims of adrenalin chloride in normal saline, and the blood pressure was recorded at intervals until it was found that there was no further rise. This was roughly $1-1 \frac{1}{2}$ hours after injection. Some cases responded well, the blood pressure rising $40-45 \mathrm{~mm}$. ; others to a lesser extent, with a rise of $20-30 \mathrm{~mm}$.; and in some there was no rise of blood pressure after the injection of adrenalin chloride.

When the pressure was considerably raised, then another careful observation of the retinal vessels was made and a description of them accurately noted down. 
As these experiments can be easily repeated by any ophthalmic surgeon, further details are not of any value.

From this artificial raising of the blood pressure, we observed in the retina :-

1. Increased fulness of the arteries.

2. Increased brilliancy of the light streak.

3. Increased breadth of the light streak.

4. (a) Indentation of veins, where previously not indented.

(b) Increased indentation of veins (in a few cases, very much increased), where previous slight indentation existed.

5. The reduction of all these signs on the return of the blood pressure to its former level.

From long experience, and from the above experiments, I think it is even possible to indicate roughly the actual height of the blood pressure in $\mathrm{mm}$. of mercury from the observation of the retinal vessels alone.

Where there are no definite signs of sclerosis, I think :-

(a) Very slight indentation of veins, full arteries with broad light streak, indicate $145-150 \mathrm{~mm}$.

(b) Very brilliant broad light streak with deeper indentation and slight signs of obstruction indicate $150-160 \mathrm{~mm}$.

(c) Very brilliant broad light streak with apparent obliteration of veins indicate $160-180 \mathrm{~mm}$.

Where the signs of advanced sclerosis are present, the veins may be indented and nipped at lower tensions.

In conclusion, there are, I think, one or two pitfalls which it is necessary to avoid.

\section{1.- The pitfall of faulty examination.}

In a case of high arterial pressure, it is frequently a matter of great difficulty to ascertain whether thickening of the vessel wall is present or not by a digital examination of the superficial vessels. It is here that the ophthalmoscope plays so important a part. The vessels can be seen as they are in life, and by the direct method of examination the image becomes magnified about 14 times. Hence the skilled ophthalmoscopist is able to detect change from the normal of a very slight amount, although to the inexperienced observer only very gross changes are detectable.

Here lies the pitfall.--Errors of refraction, especially high errors, blur the picture, and unless they are carefully corrected, the interpretation of what appears is fallacious.

\section{2.-The pitfall of acute toxcemia.}

In patients suffering from very severe toxæmia, we may see in the retina :-

(a) Broad arteries. 
(b) Increased light streak.

(c) Engorged veins.

(d) Some very slight indentation of these engorged veins. Yet the blood pressure, as shown by the manometer, is abnormally low.

Such a condition one may see, for instance, in an acute Bright's disease, a very severe influenza, etc.

The explanation of the appearance of the retinal vessels is, I think, due to :-

(a) Relaxation of the vaso-motor control of the arteries ;

(b) Dilatation of the heart, with loss of its muscular power ;

(c) Consequent engorgement and stagnation of the venous system.

This general condition is due to the toxin circulating in the blood. In several of these cases I have listened to the heart's action, and found the sounds so weak as to be almost inaudible. On administering small doses of digitalis, with an apparent general improvement in the patient, the blood pressure has gone up with a jump, say, from 90 to 140 (this without any marked diminution of the albumin excreted in the albuminuric cases).

\section{The pitfall of the failing heart.}

A somewhat similar pitfall exists in cases of prolonged high tension with sclerosis, in which the heart's action suddenly begins to flag.

In such a case the retinal signs would indicate to the careful observer a fall in the blood pressure from what it previously had been, yet those signs would point to a higher pressure than the manometer would give.

Why is this? Again because-

1. With the failing heart, the stagnation of the blood stream produces swollen veins.

2. Owing to the hardness of their walls the arteries remain rigidly fixed.

3. The swollen veins appear to be obstructed by the rigid arteries.

Keeping in mind these three liabilities to err, viz. :

Faulty examination;

Acute toxæmia ;

The failing heart:

I think it is possible for the ophthalmic surgeon to distinguish by means of the ophthalmoscope between increased blood pressure and arterio-sclerosis, and to base his prognosis and treatment thereon. 